\title{
Patterns of Mortality Occurrence in a Cardiology Unit of a Low-Income Country: A Critical Analysis at the Yaoundé Central Hospital
}

\author{
Liliane Mfeukeu Kuaté1,2, Mazou Ngou Temgoua ${ }^{*}$, Hamadou Ba ${ }^{1}$, Chris Nadège Nganou ${ }^{1,2}$, \\ Doriane Mbono², Bidias Ndongo' ${ }^{1}$, Joel Nouktadie Tochie1, Eugene Sobngwi1 \\ ${ }^{1}$ Faculty of Medicine and Biomedical Sciences, University of Yaoundé 1, Yaoundé, Cameroon \\ ${ }^{2}$ Cardiology Unit, Central Hospital of Yaoundé, Yaoundé, Cameroon \\ Email: mfeukeuliliane@gmail.com, *neurotemgoua@yahoo.fr, drhamadouba@yahoo.fr, cn_nganou@yahoo.fr, \\ dorianembono@yahoo.fr, bidiasdavid@yahoo.fr, joeltochie@gmail.com, sobngwieugene@yahoo.fr
}

How to cite this paper: Kuaté, L.M., Temgoua, M.N., Ba, H., Nganou, C.N., Mbono, D., Ndongo, B., Tochie, J.N. and Sobngwi, E. (2021) Patterns of Mortality Occurrence in a Cardiology Unit of a Low-Income Country: A Critical Analysis at the Yaoundé Central Hospital. World Journal of Cardiovascular Diseases, 11, 126-134.

https://doi.org/10.4236/wjcd.2021.112014

Received: January 14, 2021

Accepted: February 19, 2021

Published: February 22, 2021

Copyright $\odot 2021$ by author(s) and Scientific Research Publishing Inc. This work is licensed under the Creative Commons Attribution International License (CC BY 4.0).

http://creativecommons.org/licenses/by/4.0/

(c) (i) Open Access

\begin{abstract}
Background: In-hospital mortality is high in low-income countries. Currently, little is known in Cameroon concerning the characteristics of patients who die in cardiology units. Our objectives were to determine the in-hospital mortality rate; describe the general characteristics of death patients, and factors associated with mortality. Material and Methods: We conducted a retrospective cross-sectional study by reviewing the medical records of all patients admitted to the cardiology unit of the Yaoundé Central Hospital (CHY) between January 2018 and January 2019. The files of all death patients were studied for socio-demographical, clinical and therapeutical variables. Bivariate analysis was conducted to order to check the association between independents variables and time of death. A p-value $<0.05$ was considered statistically significant. Results: A total number of 860 patients were admitted in the cardiology unit of CHY during the study period. Amongst the 860 patients admitted 78 had a fatal outcome, hence, an in-hospital mortality rate of $9.06 \%$. The male gender was predominant amongst the deceased patients $(\mathrm{n}=$ 45). The mean age at death was $69 \pm 15.19$ years. The median time before death was 6 days and they ranged between 1 to 25 days. Hypertension was the most frequent comorbidity (65.4\%). Stroke was the principal cause of admission (40.3\%), whereas the main presenting complaint was dyspnea (26.9\%). Before being admitted to the cardiology department, the majority of the deceased patients were from the emergency department. The major clinical sign of death was respiratory distress (39.74\%). Shock on admission was the sole
\end{abstract}


factor found to be associated with the mean time of death $(p=0.012)$. The patients with deep venous thrombosis compared to other diagnoses were less like to die early $(r=16, p=0.016)$. Conclusion: The patient admitted in the cardiology unit of Yaoundé Central Hospital died mainly from stroke and the death is earlier when the patient has signs of shock on admission. These results emphasize the need for a good primary evaluation at the emergency room, to better manage patients with cardiovascular diseases in the cardiology ward.

\section{Keywords}

Mortality Occurrence, Low Income Country, Yaoundé Central Hospital, Critical Analysis

\section{Background}

In-hospital death occurrence is frequently linked to clinical characteristics of the patients, but also the weakness of the health care system [1] [2]. In sub-Saharan Africa, the incidence of in-hospital cardiovascular disease related-death is high and depends on various etiologies, $28.7 \%$ for stroke and 3.9\% - 61.7\% for heart failure [3] [4]. In Cameroon, there is no data on the global in-hospital death in specialized units, but a recent study conducted by Boombhi et al in two tertiary hospitals found a prevalence of $12 \%$ for cardiovascular diseases [5]. In practice, in cardiology units of low-income countries, many patients are hospitalized for non-cardiovascular problems and may die because of the unavailability of specialized clinicians to adequately manage these patients. An unpublished data in Yaoundé Central hospital found a prevalence of $7 \%$ of all-cause mortality at the cardiology unit, but still, now no data are available to explain this mortality. We undertook an audit in a cardiology unit of a low-income country to anticipate some death in our context.

Our general objective was to describe the epidemiological and clinical pattern of all-cause mortality in the cardiology unit of Yaoundé Central Hospital Cameron. Specifically, we sought to determine the in-hospital mortality rate, describe de general characteristics of death patients, and factors associated with mortality.

\section{Material and Methods}

\section{Study design, setting and population}

We conducted a retrospective cross-sectional study between January 2018 and January 2019 at the cardiology department of the Yaoundé Central Hospital (CHY). The files of all death patients independently of the cause were consecutively recruited during the study period and analyzed for relevant socio-demographic, clinical and therapeutical data. All incomplete files were excluded.

\section{Study variables}

The important variables of this study were categorized as followed: Sociode- 
mographical characteristics: age, sex; Clinical data: co-morbidities, date of admission, date of death, diagnosis of admission, retained diagnosis, complications; Therapeutical data: adherence to treatment, the delay before management in the unit.

\section{Procedure}

After obtaining administrative authorization, we proceeded to recruitment chart review of files. The register of the cardiology unit helped us to track all the death patients during the study period. After identification of these patients, the various file was checked to complete information. For important lacking data, we contacted the next of kin of the patient through phone calls.

\section{Statistical analysis}

Statistical analysis was performed using EPI Info version 7. Quantitative variables were represented as mean or median with standard deviation or interquartile range respectively depending on symmetrical distribution or not. Qualitative variables were represented in proportions. Bivariate analysis was conducted to check the association between independents variables and median time of death. A Pearson correlation test was also used for 2 continuous variables. A p-value $<0.05$ was considered statistically significant.

\section{Ethical consideration}

Ethical Clearance of the Faculty of Medicine and Biomedical Sciences and Administrative authorizations of Yaoundé Central Hospital were obtained before recruitment

\section{Results}

A total number of 860 patients were admitted in the cardiology unit of CHY from January 2018 to January 2019. 78 of them died, giving a mortality rate of $9.06 \%$.

\section{General characteristics of the death patient}

The male gender was predominant in the population with a proportion of $57.7 \%(\mathrm{n}=45)$. The mean age of the dead patients was $69 \pm 15.19$ years. The median time before death was 6 days and the range between $1-25$ days.

\section{Clinical characteristics of the patient}

Hypertension was the most frequent comorbidity in the population (65.4\%), Stroke was the principal diagnostic on admission (40.3\%) mainly ischemic stroke $(52 \%)$ than hemorrhagic (48\%). The patients had frequent respiratory distress on the admission (26.9\%) Table 1. Death patients came generally from the emergency room (Figure 1). The major clinical presentation before death was respiratory distress (39.74\%) Figure 2. In the group of patients with heart failure, respiratory distress was always the major clinical presentation Table 2.

\section{Therapeutic characteristics}

Most of the patients were treated early on admission into the unit and adhered to the treatment (Table 3).

Factors associated with the time of death

There was a slight positive correlation between age and the mean time of death 
(Figure 3). Only Shock on admission was associated with the median time of death in bivariate analysis $(\mathrm{p}=0.012)$ Table 4 . Patients with signs of shock on admission died earlier than those without shock. There was a strong positive correlation between Deep Venous Thrombosis (DVT) and the medium time of

Table 1. Clinical characteristics of death patients.

\begin{tabular}{|c|c|c|}
\hline Variables & Number $(\mathrm{N}=78)$ & Percentage (\%) \\
\hline \multicolumn{3}{|l|}{ Comorbidities } \\
\hline Cancer & 1 & 1.3 \\
\hline Diabete & 9 & 11.5 \\
\hline Liver disease & 4 & 5.1 \\
\hline Hypertension & 51 & 65.4 \\
\hline Renalfailure & 6 & 7.7 \\
\hline HIV infection & 3 & 3.8 \\
\hline Atrial fibrillation & 12 & 15.4 \\
\hline \multicolumn{3}{|l|}{ Diagnosis on admission } \\
\hline Heart Failure & 29 & 37.7 \\
\hline Hypertensive emergency & 1 & 1.3 \\
\hline Stroke & 31 & 40.3 \\
\hline Renal Failure & 1 & 1.3 \\
\hline Deep vein thrombosis & 1 & 1.3 \\
\hline Pulmonary embolism & 3 & 3.9 \\
\hline Acute limb ischemia & 1 & 1.3 \\
\hline Acute coronary syndrome & 2 & 2.6 \\
\hline Others & 9 & 11.7 \\
\hline \multicolumn{3}{|l|}{ Clinical state on admission } \\
\hline Severe anemia & 4 & 5.1 \\
\hline Altered vigilance & 6 & 7.7 \\
\hline Convulsion & 1 & 1.3 \\
\hline Dehydration & 5 & 6.4 \\
\hline Dyspnoea & 21 & 26.9 \\
\hline Fever & 7 & 9 \\
\hline Severe hypertension & 14 & 17.9 \\
\hline Intracranial hypertension & 4 & 5.1 \\
\hline Hypotension & 11 & 14.1 \\
\hline \multicolumn{3}{|l|}{ Final diagnosis } \\
\hline Heart Failure & 30 & 39 \\
\hline Hypertensive emergency & 1 & 1.3 \\
\hline Stroke & 33 & 42.9 \\
\hline Renal Failure & 2 & 2.6 \\
\hline Deep vein thrombosis & 1 & 1.3 \\
\hline Pulmonary embolism & 2 & 2.6 \\
\hline Acute limb ischemia & 1 & 1.6 \\
\hline Acute coronary syndrome & 2 & 2.6 \\
\hline Others & & \\
\hline
\end{tabular}




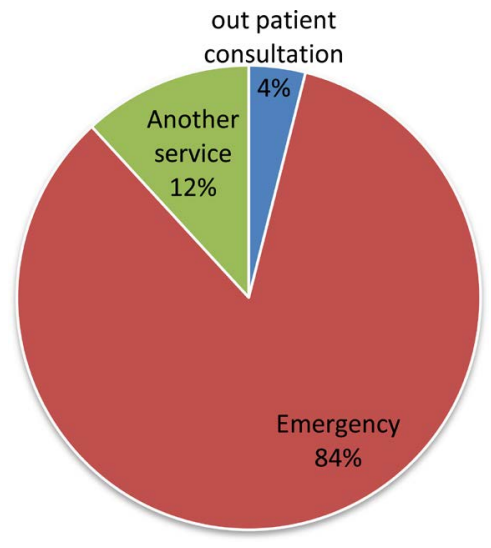

Figure 1. Distribution of the patients according to their origin.

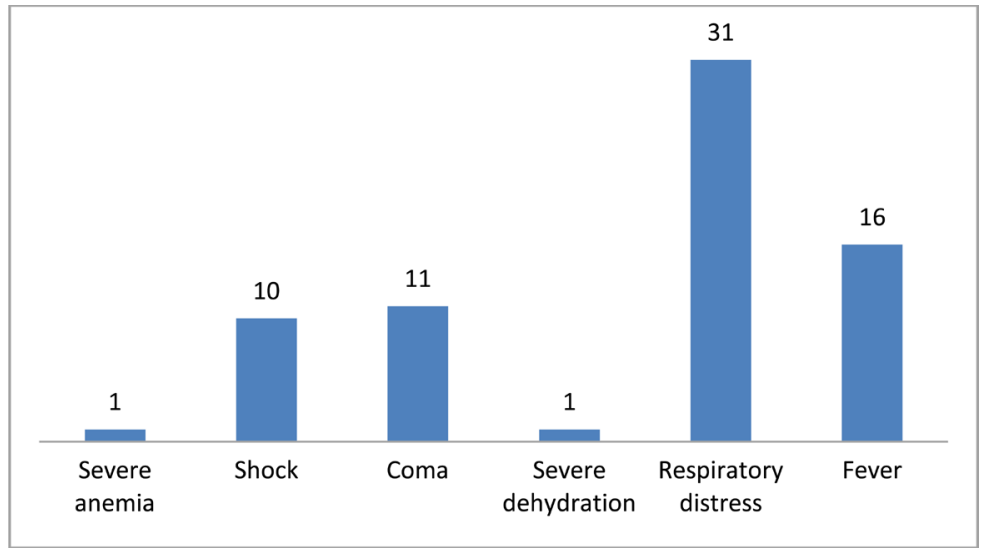

Figure 2. Clinical presentation at death.

Table 2. Summary of main clinical presentation at death period.

\begin{tabular}{ccccc}
\hline & \multicolumn{4}{c}{ Clinical presentation } \\
\cline { 2 - 5 } Diagnosis & $\begin{array}{c}\text { Alter } \\
\text { consciousness }(\%)\end{array}$ & $\begin{array}{c}\text { Shock } \\
(\%)\end{array}$ & $\begin{array}{c}\text { Respiratory } \\
\text { distress }(\%)\end{array}$ & $\begin{array}{c}\text { Fever } \\
(\%)\end{array}$ \\
\hline $\begin{array}{c}\text { Heart failure }(\mathrm{N}=29) \\
\text { Stroke }(\mathrm{N}=32)\end{array}$ & $2(7)$ & $5(17)$ & $13(44.8)$ & $2(7)$ \\
Hypertensive emergency & $8(25)$ & 0 & $10(31)$ & $11(34)$ \\
$\quad(\mathrm{N}=1)$ & 0 & $1(100)$ & 0 & $1(100)$ \\
Renal failure $(\mathrm{N}=1)$ & 0 & $1(100)$ & 0 & 0 \\
Pulmonary embolism $(\mathrm{N}=3)$ & 0 & 0 & $2(67)$ & $1(33)$ \\
Acute limb ischemia $(\mathrm{N}=1)$ & 0 & 0 & $1(100)$ & 0 \\
Myocardial infarction $(\mathrm{N}=1)$ & 0 & $1(100)$ & 0 & 0
\end{tabular}

Table 3. Therapeutic characteristics.

\begin{tabular}{ccc}
\hline Variables & Number $(\mathbf{N}=\mathbf{7 8})$ & Percentage (\%) \\
\hline Mean time before treatment (in days) & & \\
$<3$ & 68 & 87.2 \\
$\geq 3$ & 10 & 12.8 \\
\hline Adherence to treatment & 66 & 84.6
\end{tabular}




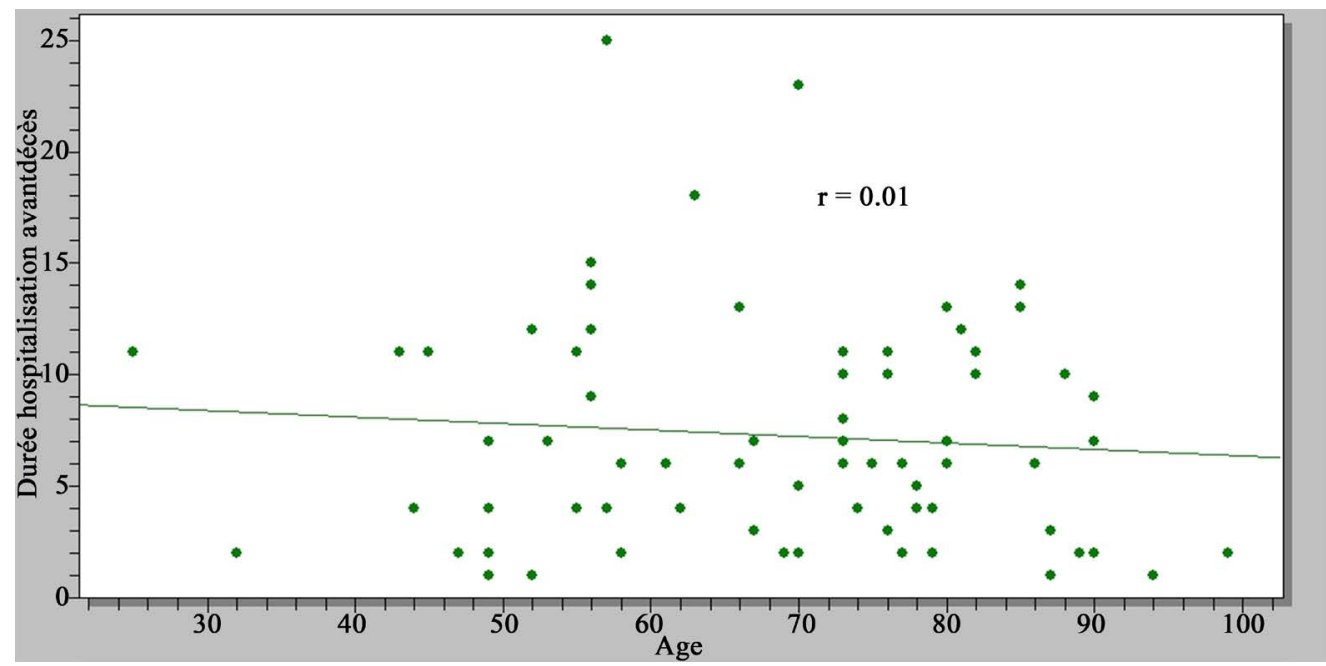

Figure 3. Relationship between mean time of death and age.

Table 4. Factors associated with median time of death.

\begin{tabular}{|c|c|c|}
\hline Variables & Median time (IQ range) in days & $\mathrm{p}$ value \\
\hline \multicolumn{3}{|l|}{ Gender } \\
\hline Male/Female & $6(4-10) / 6.5(3-11)$ & 0.88 \\
\hline \multicolumn{3}{|l|}{ Comorbidities } \\
\hline Hypertension ( $\mathrm{Yes} / \mathrm{No}$ ) & $6(3-10) / 7(4-11)$ & 0.61 \\
\hline Renal failure ( Yes/ No) & $7.5(4-11) / 6(3-10.5)$ & 0.85 \\
\hline Chronic respiratory failure ( $\mathrm{Yes} / \mathrm{No}$ ) & $11(2-14) / 6(3-10)$ & 0.51 \\
\hline LiverFailure $(Y e s / N o)$ & $11(7-12.5) / 6(3-10.5)$ & 0.30 \\
\hline \multicolumn{3}{|l|}{ Origin } \\
\hline External consultation/Emergency/Another service & $11(9-11) / 6(3.5-10.5) / 4(3-7)$ & 0.51 \\
\hline \multicolumn{3}{|l|}{ Clinical state at Entry } \\
\hline Severe anemia (yes/no) & $8(5.5-12) / 6(3-11)$ & 0.56 \\
\hline Altered vigilance (yes/no) & $7(6-11) / 6(3-10.5)$ & 0.86 \\
\hline Convulsion (yes/no) & $7(5-11) / 6(3-11)$ & 0.96 \\
\hline Dehydration (yes/no) & $4(2-9) / 6(4-11)$ & 0.61 \\
\hline Dyspnoea (yes/no) & $4(2-6) / 6(4-11)$ & 0.99 \\
\hline Fever (yes/no) & $6(2-11) / 6(4-10)$ & 0.51 \\
\hline Severe hypertension (yes/no) & $3.5(3-4.5) / 6(4-11)$ & 0.87 \\
\hline Intracranial hypertension (yes/no) & $6.5(4-11) / 6(3-11)$ & 0.15 \\
\hline${ }^{\star}$ Signs of shock (yes/no) & $6(3-10) / 10(6-14)$ & 0.012 \\
\hline
\end{tabular}

*Signs of shock: hypotension, cold extremities, rapid pulse, oliguria, altered vigilance.

death. Patient with DVT were less like to die earlier compared to patients with other clinical presentations on admission $(\mathrm{r}=16 ; \mathrm{p}=0.016)$ Table 5.

\section{Discussion}

In-hospital mortality is high in Low-Income Countries (LICs) [1] [3]. There is a 
Table 5. Correlation between entry diagnostic and with medium time of death.

\begin{tabular}{ccc}
\hline Diagnosis & Correlation coefficient $\mathbf{r}$ & p value \\
\hline Heart failure & 1.172 & 0.80 \\
Hypertensive emergency & 4 & 0.54 \\
Stroke & -1.16 & 0.80 \\
Renal failure & 2 & 0.75 \\
Deep vein thrombosis & 16 & 0.016 \\
Pulmonary embolism & -2.66 & 0.61 \\
Acute limb ischemia & -1 & 0.87 \\
Acute coronary syndrome & 7 & 0.1 \\
\hline
\end{tabular}

dearth of data in our setting on the characteristics of patients who die in Cardiology units. We conducted this study to have baseline data. We found that the prevalence of death in the cardiology unit was high. The patients who died were generally old, had hypertension as the major comorbidity. Stroke was the main diagnosis on admission, while dyspnoea was the main clinical presentation before death. The patient generally died at the end of the first week of hospital stay, despite early management and good adherence to treatment. Shock on admission reduced the time before death. The prevalence of death was high. Ratcliffe et al. in their coronary care unit in the USA found a mortality rate of $5.6 \%$; their patients had an average age of 67 years and two-third were males as seen in the current study [6]. The great difference with our study is the causes of the admission. Contrary to our study, all of their patients have coronary disease. Half of our patients had a stroke which is not a purely cardiac disease and could partially explain this high prevalence of death because the appropriate service for stroke is neurology or intensive care unit, not cardiology. The socio-economic gap between the two countries, Cameroon and the USA notably in terms of human and material resources could also explain the difference in death rate. Wajner et al. found in a selective population of patients with heart failure in Brazilan in-hospital mortality rate of $17.6 \%$ [7]. Heart failure is known as a serious public health problem and the leading cause of death in cardiology units [4]. The mortality rate in this specific group will always be greater than the heterogeneous group like our setting. Some authors showed that an inadequate reference is one of the major causes of in-hospital death [8]. This emphasizes therefore the need for regular refresher courses for health care providers in the emergency room. Another explanation for this high mortality could be the critical condition of some patients in the cardiology unit. Patients with hypotension or shock are generally better managed in the intensive care unit and the presence of this clinical feature can easily precipitate death. At the period of death, the predominance of convulsion is explained by the fact that stroke was the first diagnostic on admission. Respiratory distress is the main clinical feature because many cardiovascular emergencies are manifested by dyspnea like heart failure, pulmonary 
embolism or pericarditis. But it is also important to take into consideration the role of lacking oxygen support system in the service like in many non Intensive Care Unit (ICU) in developing countries. The fact that treatment was early and adherence good in our population reinforces the idea that two main factors should be taken into account: the critical condition of the patient on admission and questioning about appropriate treatment in the unit.

The limit of this study is the fact that there was no control group to compare the data, but this primary data shows us the necessity of a better transfer system from the emergency unit to the cardiology unit and equipment of the unit to manage some critical conditions like hypotension, convulsions and dyspnoea.

\section{Conclusion}

The patients admitted to the cardiology unit of Yaoundé Central Hospital died mainly from Stroke and the death is earlier when patients have a state of shock on admission. This result emphasizes the need for a good primary evaluation at the emergency unit to address the patients to the appropriate unit.

\section{Availability of Data and Materials}

The datasets used and analyzed during the current study are available from the corresponding author on request.

\section{Authors' Contributions}

LMK and MNT: study conception and design, data collection and analysis, interpretation of results, manuscript writing and critical revision. HB, CNN, DM, BN, MJE, JNT and SK: data collection and analysis, interpretation of results and critical revisions. ES: Supervising all the process. All the authors read and approved the final version of the manuscript.

\section{Acknowledgments}

The authors acknowledge the administrative authorities of the Yaoundé Central Hospital of Cameroon for authorizing them to carry out this study.

\section{Conflicts of Interest}

The authors declare no conflicts of interest regarding the publication of this paper.

\section{References}

[1] Cao, J.N., Liu, W.X., Zhu, J.J. and Zhao, H. (2015) Risk Factors and Clinical Characteristics of In-Hospital Death in Acute Myocardial Infarction with IABP Support. International Journal of Clinical and Experimental Medicine, 8, 8032-8041.

[2] Flaatten, H., Bratteb, G., Alme, B., Berge, K., Rosland, J.H., Bertelsen, B. et al. (2017) Adverse Events and In-Hospital Mortality: An Analysis of All Deaths in a Norwegian Health Trust during 2011. BMC Health Services Research, 17, Article No. 465. https://doi.org/10.1186/s12913-017-2417-7

[3] Labodi, L.D., Kadari, C., Valentin, Y.N., Christian, N. and Jean, K.B. (2017) In- 
tra-Hospital Mortality of Stroke and Its Predictive Factors in a Reference Hospital in Ouagadougou, Burkina Faso. Brain Nerves, 1, 1-6.

https://doi.org/10.15761/JBN.1000113

[4] Nyaga, U.F., Bigna, J.J., Agbor, V.N., Essouma, M., Ntusi, N.A.B. and Noubiap, J.J. (2018) Data on the Epidemiology of Heart Failure in Sub-Saharan Africa. Data in Brief, 17, 1218-1239. https://doi.org/10.1016/j.dib.2018.01.100

[5] Boombhi, J., Menanga, A., Doualla, J.P., Hamadou, B., Kuate, L., Ntep, M. and Kingue, S. (2013) Prevalence and mortality of Cardiovascular disease in Cameroon: Case of two tertiary Hospitals in Yaounde. Cardiologie Tropicale. http://tropical-cardiology.com

[6] Ratcliffe, J.A., Wilson, E., Islam, S., Platsman, Z., Leou, K., Williams, G., Lucido, D., et al. (2014) Mortality in the Coronary Care Unit. Coronary Artery Disease, 25, 60-65. https://doi.org/10.1097/MCA.0000000000000043

[7] Wajner, A., Zuchinali, P., Olsen, V., Polanczyk, C.A. and Rhode, L.E. (2017) Causes and Predictors of In-Hospital Mortality in Patients Admitted with or for Heart Failure at a Tertiary Hospital in Brazil. Arquivos Brasileiros de Cardiologia, 109, 321-330. ahttps://doi.org/10.5935/abc.20170136

[8] Escobar, G.J., Greene, J.D., Gardner, M.N., Marelich, G.P., Quick, B. and Kipnis, P. (2011) Intra-Hospital Transfers to a Higher Level of Care: Contribution to Total Hospital and Intensive Care Unit Mortality and Length of Stay. Journal of Hospital Medicine, 6, 74-80. https://doi.org/10.1002/jhm.817
Abbreviations
CHY: Central Hospital of Yaoundé
DVT: Deep Venous Thrombosis
ICU: Intensive Care Unit
LICs: Low-income Countries 